\title{
中空型縱渦の不安定挙動*
}

後藤田 浩 ${ }^{* 1}$, 橋場 優 ${ }^{* 2}$, 比江島 俊彦 ${ }^{* 3}$, 松谷 一路 ${ }^{* 2}$, 西岡 通男 ${ }^{* 4}$

\section{Instability of a Hollow-Type Streamwise Vortex}

\author{
Hiroshi GOTODA, Yu HASHIBA, Toshihiko HIEJIMA, Kazumichi MATSUTANI \\ and Michio NISHIOKA ${ }^{* 4}$ \\ ${ }^{* 4}$ Department of Aerospace Engineering, Osaka Prefecture Univ. \\ 1-1 Gakuencho, Nakaku, Sakai-shi, Osaka, 599-8531 Japan
}

We experimentally investigate the unstable behavior of a large scale hollow-type streamwise vortex which has a solid-rotation type distribution of vorticity existing only in an annular region initially, focusing on how the large scale vortex breaks down into small scales downstream. With increasing the intensity of the initial vorticity, the large scale hollow vortex undergoes significant transition from a steady-state to nonlinear stages governed by coherent vortices through the primary linear instability. When the periodic motions due to the primary instability grow and redistribute the vorticity, a rotating vorticity field of polygonal shape begins to develop. This is an important precursor to the nonlinear evolution of the instability of hollow-type streamwise vortex. The flow structures we obtained in this work allow the fluid mixing to be significantly enhanced even under low Reynolds numbers. The present study also shows that the ratio of maximum azimuthal velocity to mean axial velocity is important as a governing flow-similarity parameter. This finding is reasonable as the cited swirl velocity ratio is directly proportional to the ratio of vortex Reynolds number to axial flow Reynolds number.

Key Words : Hollow-Type Streamwise Vortex, Coherent Vortex, Inflectional Instability, Mixing Enhancement, Swirling Jet

\section{1. 緒言}

今日のエネルギー・環境などの広範な工学分野において，高効率の流体混合を可能とする流体制御法の開発は 重要な研究課題である。一般に，流体混合を促進させる手段としては，乱流渦の利用が最も合理的と言える．乱 流のカスケード過程によってスケールの大きい渦からスケールの小さな渦が無数生み出され, 渦の複雑な 3 次元 運動が流体要素間の接触面積を著しく増大させることで分子レベルの混合が一気に進む. Dimotakis ${ }^{(1)}$ は高い混 合能の乱流場が生まれるレイノルズ数（乱流をつくる渦度場の代表速度と代表長さで定義）の臨界值を調べ，レ イノルズ数が 1 2×10 4 を超えると, 十分に発達した乱流場の激しい混合状態が維持されるようになり，このとき のエネルギースペクトルはコルモゴロフの-5/3 乗則に従うことを明らかにしている．そして Dimotakis ${ }^{(1)}$ はこの ような発達した乱流への遷移を“混合遷移”と呼び，異種流体の混合促進の基準を議論している，一方，化学反 応器や燃焼器の開発など, 高効率の流体混合が望まれる工学分野では, 低レイノルズ数流れにおいても有効な混 合促進の流体制御技術が求められている．このことは，混合遷移の臨界值よりも小さい低レイノルズ数の領域に おいて, 流れの混合能を高める流体制御法が必要であることを意味する. 勿論, それが高いレイノルズ数の領域 でも役立つ制御法であることが望まれる，本研究ではこのような低レイノルズ数の領域において流体混合を促進

\footnotetext{
* 原稿受付 2011 年 9 月 30 日

*1 正員, 立命館大学 理工学部 機械工学科（广525-8577 滋賀県草津市野路東 1-1-1）

*2 立命館大学大学院 理工学研究科 創造理工学専攻 (T525-8577 滋賀県草津市野路東 1-1-1)

*3 正員, 大阪府立大学大学院 工学研究科 航空宇宙工学分野

（干599-8531 大阪府堺市中区学園町 1-1）

*4 正員, 永年会員, 大阪府立大学大学院 工学研究科 航空宇宙工学分野 ( (599-8531 大阪府堺市中区学園町 1-1)

E-mail: mt_nishioka@world.ocn.ne.jp
} 
させることを狙っているが，そのためにはどのような流れ(渦度場)に着目寸ればよいのであろうか. それは流れ の不安定性が強く, 迅速に崩壊しや寸い大スケールの渦度場を人為的に作り出すことであると思われる.

流体混合が困難である代表的な例の一つとして，超音速流がある．超音速流中では，流体要素間の接触面積を 増大させ混合を促進させるために必要な乱流運動が圧縮性の影響により著しく抑制され，乱流混合は激しく鈍化 する. この圧縮性の影響を効果的に緩和寸る流れとして，西岡ら ${ }^{(2)}$ は流れ方向に渦軸を持つ縦渦に注目し，その 中心軸から離れた環状領域のみに渦度を有する “中空型縦渦” が乱流混合を促進させる可能性を理論的に示して いる.このような渦度分布を有する縦渦は, 非圧縮混合層に類似の変曲点不安定が励起される構造を有しており, 増幅率の大きい複数モードの擋乱が成長し, 縦渦内に小スケールの組織渦が形成される ${ }^{(2)}$. そして, 複数の孤立 した組織渦が生成・合体・融合を繰り返しながら, 流体混合に有利な力オス的な流れ場が形成される. 中空型の 渦度場は, ランキン渦やガウス渦度分布を有する中実型の渦度場と比較して, 流れの不安定性が非常に強く, 迅 速でかつ一様な流体混合を可能にすると期待される，中空型の渦度場を扱った例として，線形安定性理論を用い てカルマン渦列や混合層の渦要素など, 横渦の安定性を調べた研究がある ${ }^{(3)}$. しかし, 圧縮性流れの場合は勿論 のこと, 非圧縮性流れの場合についても, 中空型縦渦場に固有の擋乱の成長・発達過程およびそれに引き続いて 起きる縦渦の崩壊過程について実験で系統的に調べた研究例はまったく無い.このような大スケールの中空型縦 渦の不安定挙動を解明することは，低レイノルズ数から高レイノルズ数までの広い範囲における高効率の流体混 合を可能とする流体制御技術の開発に貢献するとともに, 流体物理分野における流れの不安定性問題の研究発展 にも寄与すると期待される.

そこで本研究では, 混合促進の観点から大スケールの中空型縦渦の不安定挙動を実験的に明らかにすることを 目的として, 様々な渦度と循環值を持つ中空型縦渦を作ることが可能な独自の回転噴流装置を開発した. 本論文 では, 環状領域の渦度を増していくとき中空型緃渦が不安定化し, 組織渦が生まれ, そして乱流に遷移する過程 について可視化で調べた結果を報告する．なお，意図的な人為擋乱は一切用いない自然遷移を対象とする.

\section{2. 実験装置および方法}

図 1 に回転噴流装置の概略図を示す，中心噴流と環状噴流は，拡散室，整流室，ノズルを通過し，内管と外管 からそれぞれ噴出される．外管はベルトを介してスピードコントロールモーター（オリエンタルモータ社製）に よって回転し, 任意の回転数（最大值: $3000 \mathrm{rpm}$ ）を与えることが可能である. 外管の内部には内径 $1.4 \mathrm{~mm}$, 長 さ $40 \mathrm{~mm}$ のストローハニカム群が外管出口から $20 \mathrm{~mm}$ 上流の位置に設置されており，そこを通る流体に剛体的 な回転運動を与える．ストロー八ニカム群と外管は一体となって回転する．このとき，内管の外壁とストロー八 二カム群は狭い隙間を介して滑りあい, 互いに接触することはない，また，ストロー八ニカム群の後流を十分に 拡散させており，その後流が中空型縦渦の中心領域（中心噴流）と環状領域（岡体回転を伴う環状噴流）の流れ に影響しないことを確認している。 このようなタイプの回転噴流装置は，既に，旋回流を伴う予混合火炎の力才 又的挙動の解明 (4) や密度差を伴う旋回噴流の渦崩壊現象の解明 (5) にも利用されている. 本研究では, 中心噴流 と環状噴流のそれぞれに空気を用いる. 中心噴流の出口直径 (内管の内径 $D_{i}$ ) を $10 \mathrm{~mm}$, 環状噴流の出口直径 (外 管の内径 $\left.D_{o}\right)$ を $20 \mathrm{~mm}$ とする. 内管の肉厚は $1.0 \mathrm{~mm}$ である. この肉厚は $5 \mathrm{~mm}$ 手前から環状流側が削られ, 出 口厚さゼロの楔状断面をもつ. 管出口における中心噴流と環状噴流軸流成分の平均速度 $V_{i}, V_{o}$ の值は質量流量計 によって独立に設定可能であるが，本報では $V_{i}=V_{o}$ の流れに焦点を合わせており， $V_{i}=V_{o}=0.5,1.0 \mathrm{~m} / \mathrm{s}$ の流れを 調べる. 軸流レイノルズ数 $R e_{o}\left(=V_{o} D_{o} / v, v\right.$ : 空気の動粘性係数 $)$ は 666, 1332 であり，管出口の流れの状態は 層流である. また本報では, 環状領域に与える回転数 (外管の回転数) $N$ を $N=0 \sim 1600 \mathrm{rpm}$ とする. このとき, 噴流出口での環状領域の外縁における周速度 $V_{\theta, r=D o / 2}\left(=\pi D_{o} N / 60 ）\right.$ は $0 \sim 1.68 \mathrm{~m} / \mathrm{s}$, 剛体回転の渦度 $\Omega(=4 \pi N / 60)$ は $0 \sim 335 \mathrm{~s}^{-1}$, 循環 $\Gamma\left(=\pi D_{o}^{2} \Omega / 4\right)$ は $0 \sim 0.105 \mathrm{~m}^{2} / \mathrm{s}$, 渦レイノルズ数 $R e_{\Gamma}(=\Gamma \mathrm{v})$ は $0 \sim 7000$ の範囲内でそれぞれ 変化する. なお，後述する噴流横断面の可視化画像で定義した剛体回転の方向は反時計方向である.

中空型縦渦の不安定挙動を明らかにするために, 本研究ではレーザーシート法を用いて, 縦渦の渦軸に対して 垂直な断面（横断面）と平行な断面（縦断面）における中心噴流と環状噴流の挙動を調べる.レーザーの光源と しては, 最大出力 $5 \mathrm{~W}$ の連続光である Nd:Yag レーザー（日本レーザー社製, Omicron Laserage Laserprodukte 


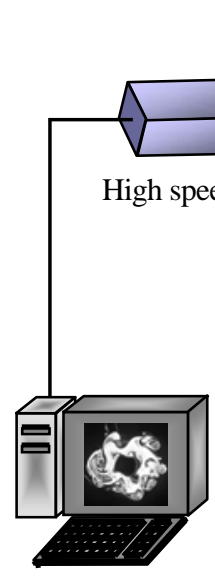

PC

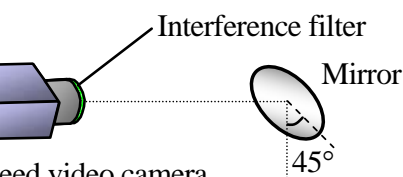

Mirror

$\mathrm{Nd}: Y a g$

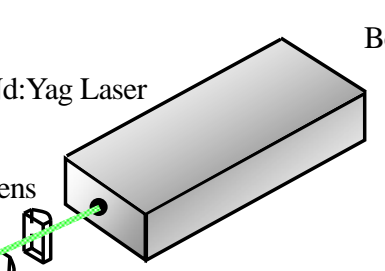

Cylindrical lens

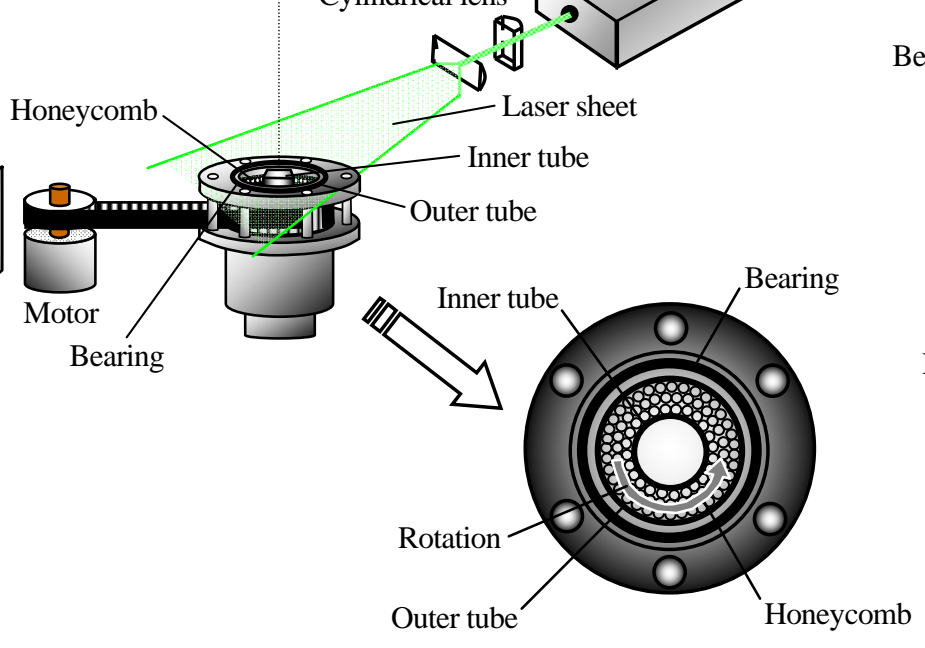

Rotating jet system (Top view seen on PC display)

Fig. 1 Experimental apparatus.

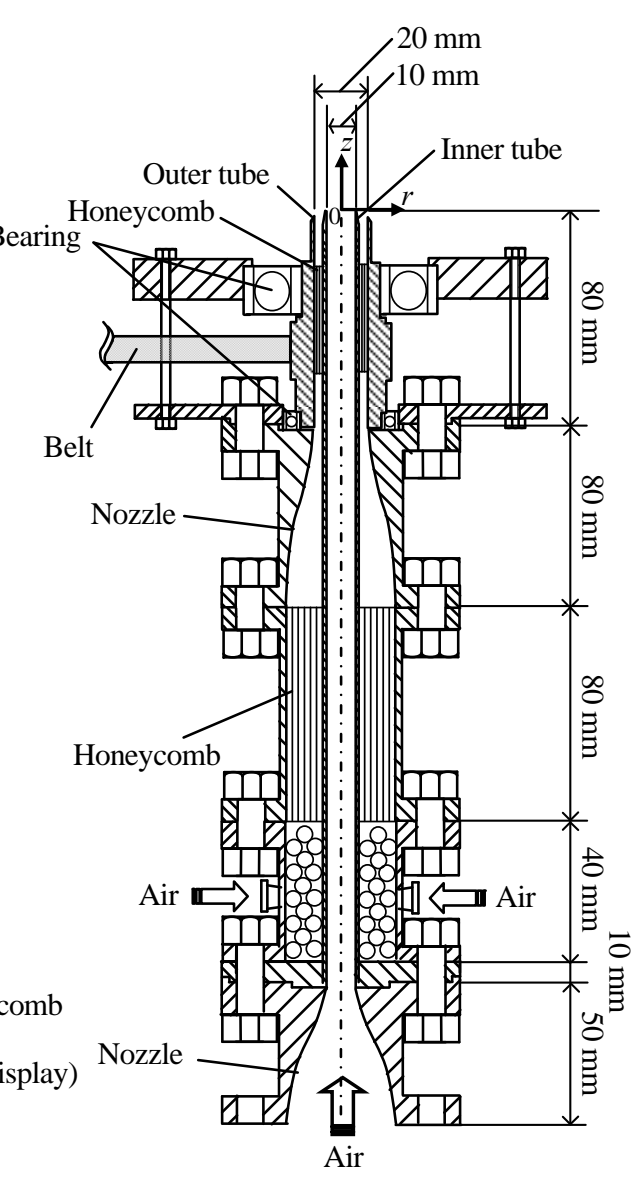

GmbHFK-LA5000）を用いる. レーザー光はシリンドリカルレンズによって厚さ約 $0.5 \mathrm{~mm}$ のレーザーシートにさ れ，テストセクションに照射される．散乱粒子として，密度が $3.9 \mathrm{~g} / \mathrm{cm}^{3}$, 一次粒子径が $20 \mathrm{~nm}$ の酸化チタン粒子 (チタン工業社製)を用い，環状噴流に混入させる．噴流は $1500 ３ 000$ frames/s の高速度ビデオカメラ（Photron 社 製 Fastcam-1024PCI 100K）を用いて, 最大シャッタースピード 1/9000 s で撮影されており, 瞬間的な噴流の二次 元断面像が得られる. 図 2 に走査型電子顕微鏡（Keyence VE-7800）によって撮影された酸化チタン粒子群の微細 構造を示す.なお, 撮影された画像の倍率は 2000 倍である.ナノサイズの酸化チタン粒子はクラスターを形成し, その平均クラスター径は $2 \mu \mathrm{m}$ 程度である. このクラスターが剛体回転（ $N=0 \sim 1600 \mathrm{rpm} ）$ する環状噴流に混入 されたとき, そのストークス数（粒子時定数を周方向の対流時間スケールで無次元化したもの） は約 0.004 以下 である. この值は 1 よりも十分小さく, 本実験の酸化チタン粒子は流れに忠実に追従すると言える. また, 図 2 に見える無数の $1 \mu \mathrm{m}$ 以下サイズのクラスターの存在は, 流れの微細構造の可視化に適している.

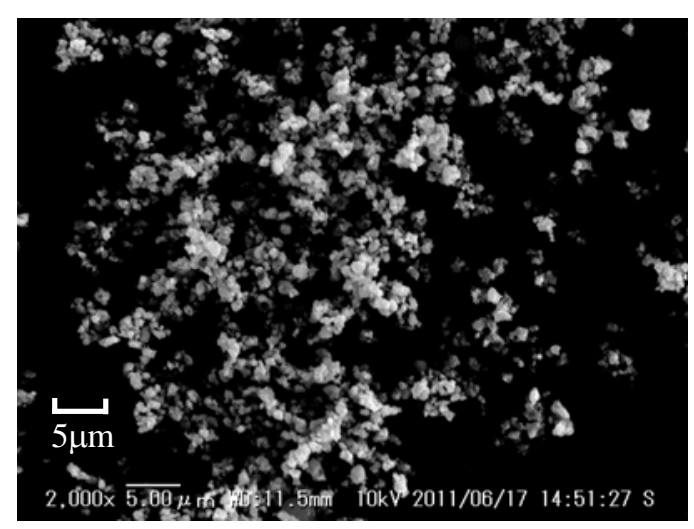

Fig. 2 Direct photograph of $\mathrm{TiO}_{2}$ particles taken by scanning electron microscope. 


\section{3. 実験結果及び考察}

$V_{i}=V_{o}=0.5 \mathrm{~m} / \mathrm{s}$ において, 環状領域に剛体回転を与えたときの環状噴流と中心噴流の縦断面像を図 3 に示す. 図中の $Z$ は外管の直径 $D_{o}$ で無次元化された流れ方向の座標を表す．環状噴流に剛体回転を与えない場合 $(N=0$ rpm), 中心噴流と環状噴流は共に平行流の状態を保ち，それに微小振幅の摚乱が重畳されている. 環状噴流外縁 の波打ちの様子からわかるように，この擋乱は下流に振幅が増幅する．流れに潜む残留乱れが同軸噴流の不安定 性で増幅されて生まれたこの擋乱の波長 $\lambda$ は $13.8 \mathrm{~mm}\left(=0.69 D_{o}\right)$, 周波数 $f$ は $26.2 \mathrm{~Hz}$, ストロ八ル数 $S_{t}\left(=f D_{o} / V_{o}\right)$ は 1.05 である. 本論文で扱う同軸噴流は， $N=0 \mathrm{rpm}$ では，このような微小振幅の擋乱が存在するが，可視化画 像が示すように実質的には層流である. 寸なわち, 環状噴流に与える剛体回転の影響 (中空型縦渦の不安定挙動) を観察する上で格好の流れ場を提供する. 剛体回転を $N=400 \mathrm{rpm}$ まで増すと, 興味深いことに $Z=1.3$ 付近にお いて内管の中心軸に対してほぼ軸対称な渦輪状の孤立した組織渦が形成される。これは，無回転における同軸噴 流の渦度場（最大周方向渦度 $300 \mathrm{~s}^{-1}$ 程度）に中空型の縦渦場（渦度 $84 \mathrm{~s}^{-1}$ 程度）が重畳されて, 渦輪をつくる不 安定性が増し, $N=0 \mathrm{rpm}$ の流れとほぼ同一波長の擋乱が強く増幅した結果と解釈される. $N=600 \mathrm{rpm}$ まで剛体 回転を増すと, 単純な渦輪の形成は抑制され, 複雑な構造の非軸対称な組織渦がより上流領域で形成される.さ らに $N=800 \mathrm{rpm}$ まで増すと, 噴流出口付近で周期的に形成された組織渦群が流下しつつ相互干涉し, 動径方向 の運動も激化して中心噴流域一も侵入し，流れは複雑化する．なお， $N=600,800 \mathrm{rpm}$ の噴流出口近傍の矢印は 後述する.

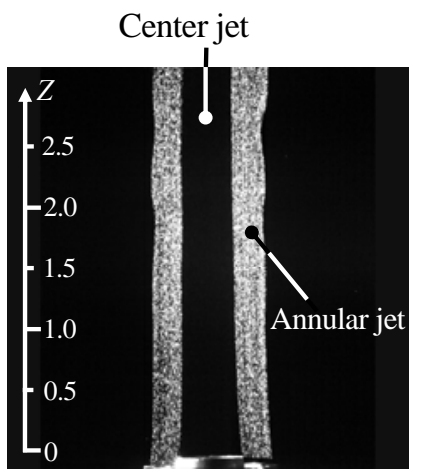

$N=0 \mathrm{rpm}$

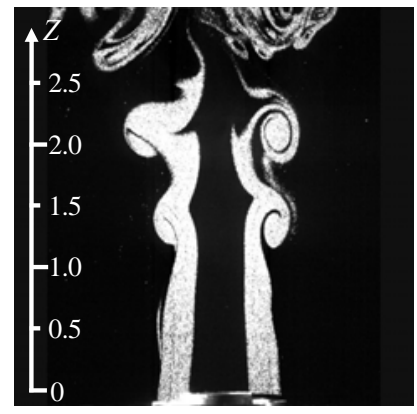

$N=400 \mathrm{rpm}$

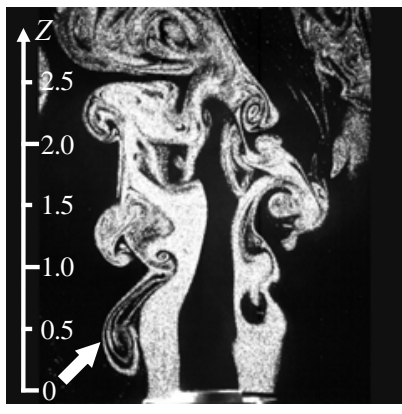

$N=600 \mathrm{rpm}$

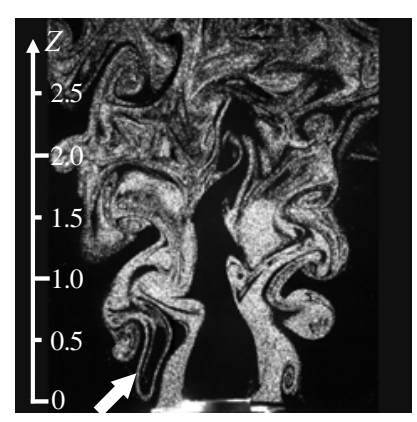

$N=800 \mathrm{rpm}$

Fig. 3 Visualization of annular jet with increasing $N$ at $V_{i}=V_{o}=0.5 \mathrm{~m} / \mathrm{s}$.

中空型縦渦場の不安定性で生まれた組織渦（孤立的な縦渦）の構造と挙動を明らかにするために可視化した環 状噴流と中心噴流の横断面像を図 4 に示す. なお， $Z=0.5$ の場合とする. $N=0,400 \mathrm{rpm}$ の場合, 図 3 の $Z=0.5$ の可視化と符合して, 環状噴流の外縁形状は円形のままである. しかし, 剛体回転を $N=550 \mathrm{rpm}$ まで増すと, 中空型縦渦場の不安定性による擋乱の成長によって環状噴流の外縁の形状は 5 角形になる． 5 角形は，選択増幅 される擋乱のモードの違いによって, 3 角形, 4 角形もしくは 6 角形になる場合も観察される. $N=600 \mathrm{rpm}$ まで 増すと, 多角形の頂点付近から 5 個の渦巻パターンが形成され，そのパターンは環状噴流に与える剛体回転の角 速度（=62.8 rad/s）の約 $45 \%$ 程度で反時計回りに回転する. 一方，渦巻きパターンは剛体回転を与える方向とは 逆向き (anti-cyclonic) の時計回りに巻き込む. この段階になると, 中心噴流の外縁の形状も 5 角形になる. $N=550$ rpm の場合と同様に，中心噴流の外縁の形状は 3 角形，4 角形もしくは 6 角形になる場合もあり，これらの多角 形パターンが準周期的に繰り返し現れる. 多角形パターンの形成は, 西岡らの数值計算 ${ }^{(2)}$ で現れるパターン形成 に対応し, さらに本研究の $D_{o} / D_{i}=2$ に対応する安定計算 ${ }^{(2)}$ の増幅率はモード 4 (4 角形) が最大である. これら のことからも中空型縦渦場の不安定性が励起されていると考えられる. さらに, $N=800 \mathrm{rpm}$ まで増すと, 中心噴 流の外縁にも渦巻きパターンを伴った組織渦が形成され始めるようになる. 中空型縦渦の不安定化による流れの 非線形発達, 特に組織渦の形成には, 環状噴流の外縁に現れる多角形の形成が前兆現象として重要であるが，こ の多角形が形成される理由は次のように推測される(2). まず, 中空型縦渦の不安定化によって擋乱が増幅される.

そして流れ場が振動的になると, 個々の流体粒子は周方向の加速・減速を周期的に繰り返し, その動径位置も周 
期的に変化する ${ }^{(2)}$. 角運動量の保存則に従うと, 不安定モードの運動によって流体粒子の一群が減速する領域に おいてそれらの動径位置が増す，最も減速された流体粒子群が集まる部分で角が生み出され，その角部で動径方 向の運動がより激しくなると, 洞巻きパターンを伴った多角形構造の形成に至るようである. 図 4 の $N=600,800$ $\mathrm{rpm}$ の渦巻パターンについて紙面に垂直な断面内のパターンとして捉えたものが図 3 に矢印で示されている. 現 段階では，多角形パターンの形成に導く変動流の構造を定量的に明らかにしていないが，今後，レーザードップ ラー流速計による周速度の時間変動の計測を行い，擋乱の構造とその特徵を明らかにする予定である.

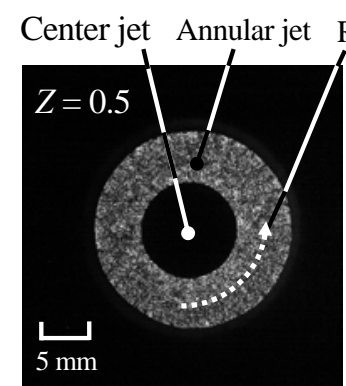

$N=0 \mathrm{rpm}$

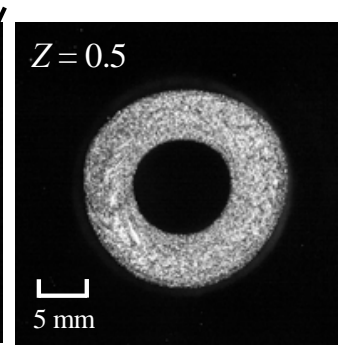

$N=400 \mathrm{rpm}$

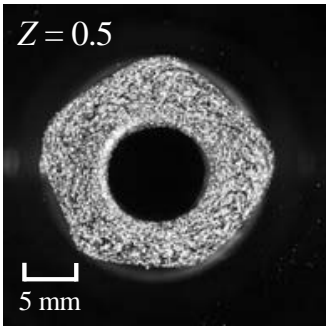

$N=550 \mathrm{rpm}$

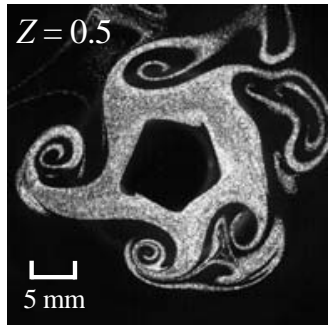

$N=600 \mathrm{rpm}$

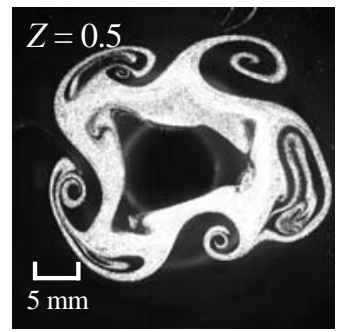

$N=800 \mathrm{rpm}$

Fig. 4 Nonlinear flow evolution of hollow-type streamwise vortex with increasing $N$ at $V_{i}=V_{o}=0.5 \mathrm{~m} / \mathrm{s}$ and $Z=0.5$.

$V_{i}=V_{o}=1.0 \mathrm{~m} / \mathrm{s}$ において, 環状領域に剛体回転を与えたときの環状噴流と中心噴流の縦断面像を図 5 に示す. $V_{i}=V_{o}=0.5 \mathrm{~m} / \mathrm{s}$ の場合と同様に, $N=0 \mathrm{rpm}$ のき, 中心噴流と環状噴流の両方は噴流出口付近において層流で平 行流の状態を保ち, それに微小振幅の擋乱が重畳されて増幅し, 渦輪が生まれる. この擋乱の波長入は $11.6 \mathrm{~mm}(=$ $0.58 D_{o}$ ), 周波数 $f$ は $60.6 \mathrm{~Hz}$ ，ストロハル数 $S_{t}$ は 1.21 である. 剛体回転を $N=800 \mathrm{rpm}$ まで増すと, $Z=1.2$ 付近 において内管の中心軸に対してほぼ軸対称な渦輪状の孤立した組織渦が形成され始め， $N=1200 \mathrm{rpm}$ にすると単 純な渦輪とは異なる非軸対称な組織渦が上流領域で形成される. さらに $N=1600 \mathrm{rpm}$ まで増すと, 噴流出口付近 で周期的に形成された組織渦群は流下しつつ相互干渉し, 動径方向の運動も激化して中心噴流域へも侵入する. これらの各現象は, $V_{i}=V_{o}=0.5 \mathrm{~m} / \mathrm{s}$ の場合とほぼ対応寸る. $V_{i}=V_{o}=1.0 \mathrm{~m} / \mathrm{s}$ において, 環状噴流に剛体回転を与 えたときの環状噴流と中心噴流の横断面像を図 6 に示寸. なお, $Z=0.5$ の場合とする. $V_{i}=V_{o}=0.5 \mathrm{~m} / \mathrm{s}$ の場合と 同様に, 環状領域の剛体回転を増していくと, 初期の層流状態からまず環状領域外縁の多角形状化が起きる. そ して，環状領域および中心噴流の外縁の多角形頂点付近から渦巻を作る組織渦の形成を経て，生成・合体・融合 を準周期的に繰り返す組織渦の集合体が生まれる. 図 5, 6 より， $V_{i}=V_{o}=1.0 \mathrm{~m} / \mathrm{s}$ の場合に組織渦が観察される回 転数 $N$ の值は $V_{i}=V_{o}=0.5 \mathrm{~m} / \mathrm{s}$ の場合(図 3, 4)の 2 倍である. このことは, 環状噴流の軸流速度が 2 倍になるとき, 環状領域の外縁における周速度 $V_{\theta, r=D o / 2}$ をほぼ 2 倍にすれば，同質の現象が観察できることを意味する.

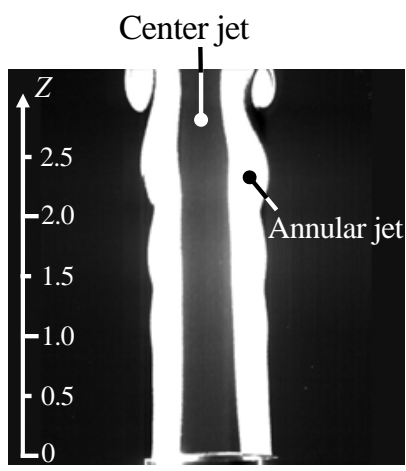

$N=0 \mathrm{rpm}$

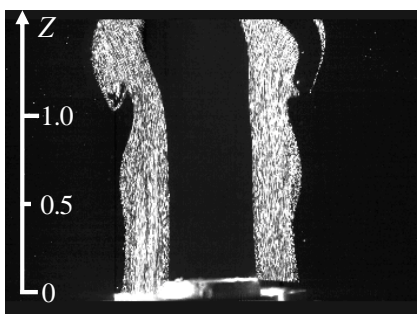

$N=800 \mathrm{rpm}$

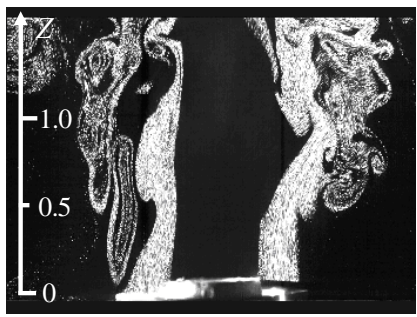

$N=1200 \mathrm{rpm}$

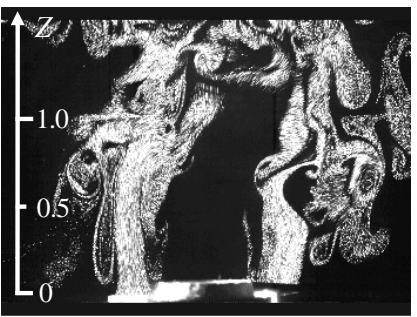

$N=1600 \mathrm{rpm}$

Fig. 5 Visualization of annular jet with increasing $N$ at $V_{i}=V_{o}=1.0 \mathrm{~m} / \mathrm{s}$. 


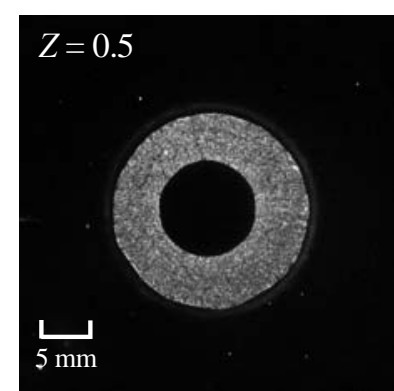

$N=0 \mathrm{rpm}$

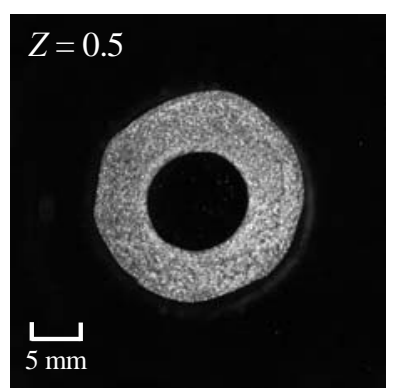

$N=800 \mathrm{rpm}$

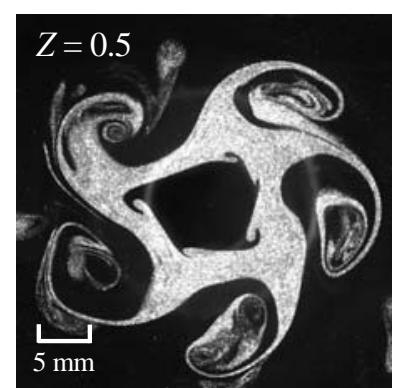

$N=1200 \mathrm{rpm}$

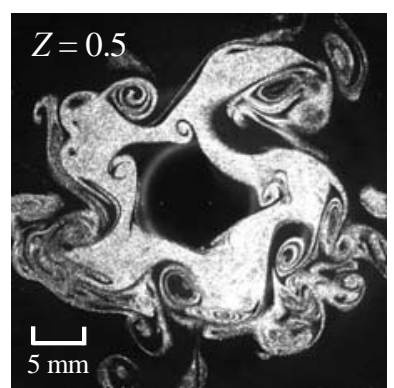

$N=1600 \mathrm{rpm}$

Fig. 6 Nonlinear flow evolution of hollow-type streamwise vortex with increasing $N$ at $V_{i}=V_{o}=1.0 \mathrm{~m} / \mathrm{s}$ and $Z=0.5$.

すなわち, 中空型縦渦場の不安定性による組織渦の発生を考察し, 記述するときには, 噴流出口における環状領 域外縁の周速度と環状噴流の軸流速度の比 $q\left(=V_{\theta, r=D o / 2} / V_{o}\right)$ が重要な因子となる. 本研究ではこの $q$ をスワール 速度比と定義する. スワール速度比は次式に示すとおり, 軸流と周方向流の時間スケール $\left(D_{o} / V_{o}\right.$ と 2/ $\left.\Omega\right)$ の比, あるいは渦レイノルズ数 $R e_{\Gamma}$ と軸流レイノルズ数 $R e_{o}$ の比で表わされる.これらの比は流れの相似因子として重要 である。

$$
q=\frac{V_{\theta, r=D o / 2}}{V_{o}}=\frac{1}{2} \frac{D_{o} / V_{o}}{2 / \Omega}=\frac{1}{\pi} \frac{R e_{\Gamma}}{R e_{o}}
$$

ここで, 組織渦が形成される直前の前兆現象（環状領域の外縁形状の多角形化）を詳しく観察してみる. 図 4, 6 からわかるように, この前兆現象は $V_{i}=V_{o}=0.5 \mathrm{~m} / \mathrm{s}$ の場合には $N=550 \mathrm{rpm}(q=1.15)$ で起き, $V_{i}=V_{o}=1.0 \mathrm{~m} / \mathrm{s}$ の場合には $N=800 \mathrm{rpm}(q=0.838)$ で起きる.この差異は渦レイノルズ数（あるいは, 循環 $\Gamma$ ) の増加で中空型 渦度場の不安定性が増すことを考慮すれば，合理的と言える．また，図７に示すように，不安定性を惹起する外 乱が強い場合には, $V_{i}=V_{o}=0.5 \mathrm{~m} / \mathrm{s}, q=1.15$ と $V_{i}=V_{o}=1.0 \mathrm{~m} / \mathrm{s}, q=0.838$ の流れはともに同質の組織渦を形成 する. つまり, 外乱が強い場合においても同じ現象が起きる.このように, 本研究で扱う現象は $q$ と渦レイノル ズ数（あるいは，軸流レイノルズ数）を支配因子として記述されることがわかる．混合促進の立場から注目する のは噴流出口付近の流れである。噴流出口近傍の流れが中空型縦渦場の不安定性に強く支配される条件を $q$ の值 で表わすことが重要となるが，外乱強度の影響も含めた詳細な調查は今後の課題である．なお，中実型縦渦の渦 崩壊・乱流遷移に関する研究 ${ }^{(6-9)}$ では, $q\left(=V_{\theta, r=D o / 2} / V_{o}\right)$ (または類似の速度比) はスワール数として扱われてい るが, 角運動量流束を用いて定義されたスワール数とは区別されるべきである. 強調すると, 本研究においては, 式(1)のとおり $q$ が軸流と周方向流の時間スケールの比あるいはレイノルズ数の比 $R e_{T} / R e_{o}$ で表わされることを示 し, その相似因子としての意義を実験で明らかにした.これは旋回噴流を扱う上で基本的に重要な知見と言える.

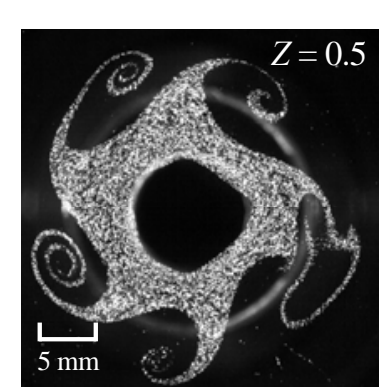

(a)

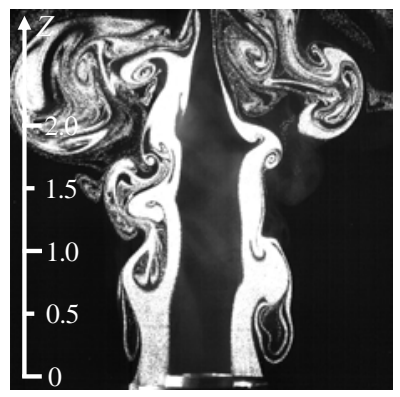

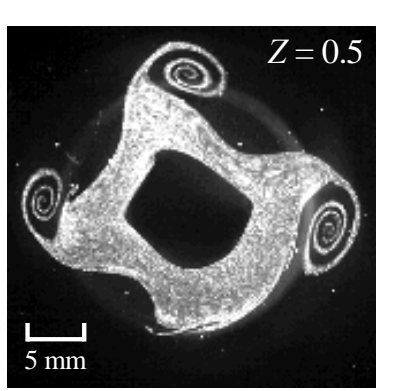

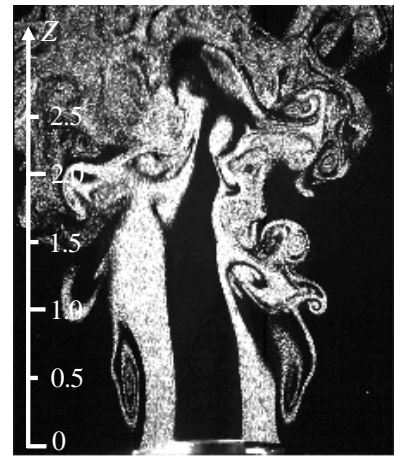

(b)

Fig. 7 Visualization of annular jets. (a) $V_{i}=V_{o}=0.5 \mathrm{~m} / \mathrm{s}$ and $N=550 \mathrm{rpm}$, (b) $V_{i}=V_{o}=1.0 \mathrm{~m} / \mathrm{s}$ and $N=800 \mathrm{rpm}$. 
$V_{i}=V_{o}=0.5 \mathrm{~m} / \mathrm{s}, q=1.68 （ N=800 \mathrm{rpm} ）$ の場合について，下流方向への組織渦の発達過程を観察した結果を図 8 に示寸. $Z=0.75$ の場合, 図 4 で示された $Z=0.5$ の場合と比較して中心噴流と環状噴流の界面で現れる小さい スケールの巻き込みパターンが顕著に現れる，そして，環状噴流外縁域で周囲大気を取り込む渦巻パターンがへ リカル状に巻きつきながら，渦巻きパターンの生成・合体・融合が繰り返される．このような複数の組織渦構造 の形成によって, 混合促進に寄与寸る流れ場が形成されていく. $Z=1.25$ の場合, $Z=0.75$ の場合と比較してより 激しい渦運動が生じる. 時刻 $t=0 \mathrm{~ms}$ ときの赤色で囲まれた部分の流体や $t=21.3 \mathrm{~ms}$ のときに青色で囲まれた部 分の流体が環状噴流から中心噴流へ侵入寸る現象が時間の経過に伴って生じ，流体混合が著しく行わる.このよ うな侵入現象が頻繁に繰り返されて，中空型縦渦の乱流遷移が進み，中心噴流と環状噴流との流体混合及び環状 噴流と周囲大気との流体混合に寄与寸る渦構造が次々生夕出される。このとき中空型縦渦の渦レイノルズ数は $R e_{\Gamma}=3500$ である. つまり, Dimotakis ${ }^{(1)}$ の混合遷移の基準よりも十分低いレイノルズ数の条件下でも流体混合に 寄与する激しい渦運動が進行しており, 中空型縦渦が混合促進に対して効果的であることを示している. $V_{i}=V_{o}=$ $1.0 \mathrm{~m} / \mathrm{s}, q=1.68\left(N=1600 \mathrm{rpm}, R e_{\Gamma}=7000\right)$ の場合の $Z=1.25$ における流れを可視化した結果を図 9 に示す. 図 9 はへリカル状に巻きついた縦渦の断面を観察したものに対応する. 上述の $V_{i}=V_{o}=0.5 \mathrm{~m} / \mathrm{s}$ の流れと比較して, 明らかに小スケールの組織渦の数が増えており, 渦レイノルズ数の増加の効果が顕著に現れている. また, $V_{i}=V_{o}$ $=0.5 \mathrm{~m} / \mathrm{s}$ の場合と同様に, 局所流れの不安定性に伴って流体が環状噴流から中心噴流入急速に侵入する現象が頻 繁に繰り返される．このような侵入現象や局所的な不安定性による組織渦の生成および組織渦間の相互干渉によ る複雑な対流運動によって, 流体塊の間の接触面積が増大し（分子レベルでの緊密な流体混合を促進させる前準 備がなされて), 流体混合が迅速に行われる.

中実型の縦渦の場合, 本論文で扱う低レイノルズ数の領域において, 図 8,9 のように噴流出口近傍で乱流場を 実現することは難しい. 例えば, 軸流速度がほぼ一様で剛体回転を伴う旋回噴流を調べた Liang and Maxworthy ${ }^{(8)}$ は軸流レイノルズ数を 1000 に保ち, 渦レイノルズ数を $R e_{\Gamma}=3460$ まで増して観察しているが, 噴流出口近傍の流 れをみると層流的である. つまり, 図 $8\left(R e_{o}=666, R e_{\Gamma}=3500\right)$ の乱流状態とは大きく異なる. この質的な違い は顕著であり, 注目に值する. なお, 前者の流れの横断面全域が乱流化するのは, 後述する渦崩壊が起きた流れ

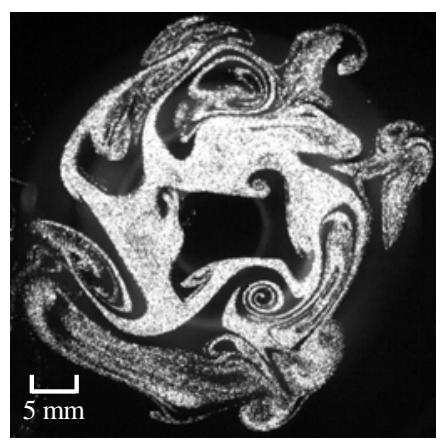

(a) $Z=0.75$

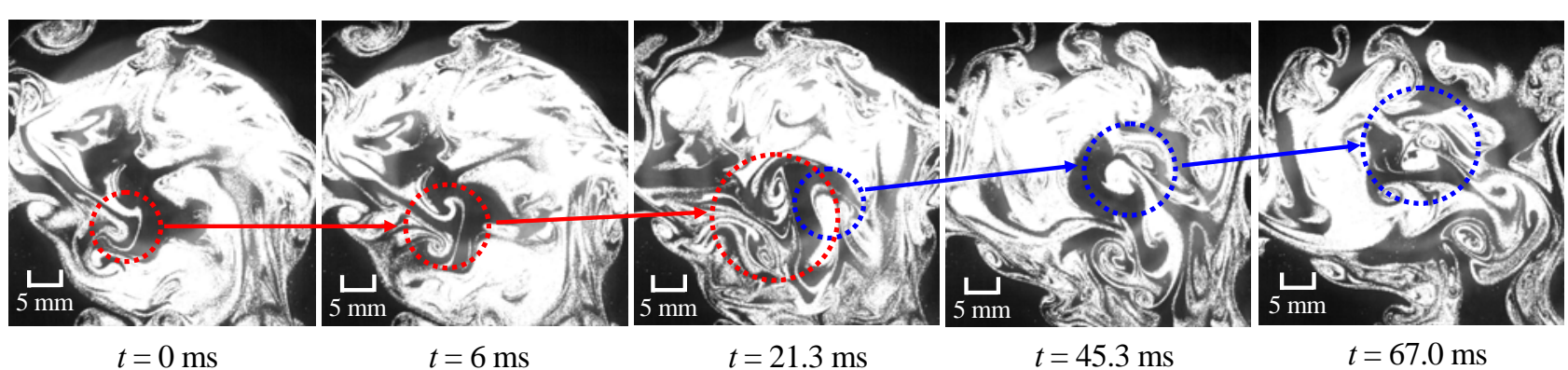

(b) $Z=1.25$

Fig. 8 Vortical structures evolving from hollow-type streamwise vortex at $V_{i}=V_{o}=0.5 \mathrm{~m} / \mathrm{s}$ and $N=800 \mathrm{rpm}$. 


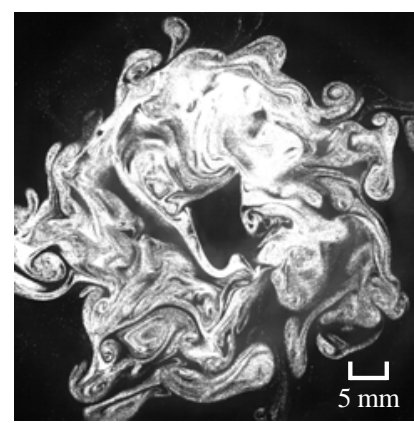

$t=0 \mathrm{~ms}$

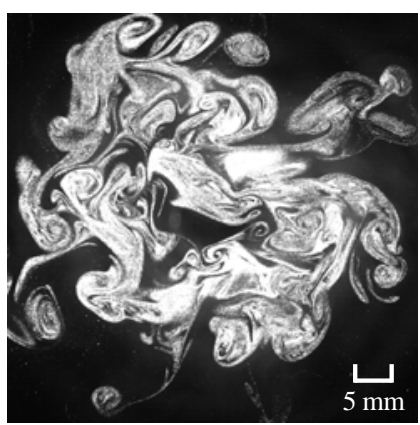

$t=41.34 \mathrm{~ms}$

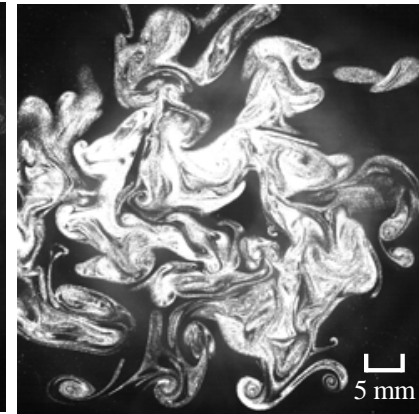

$t=679.34 \mathrm{~ms}$

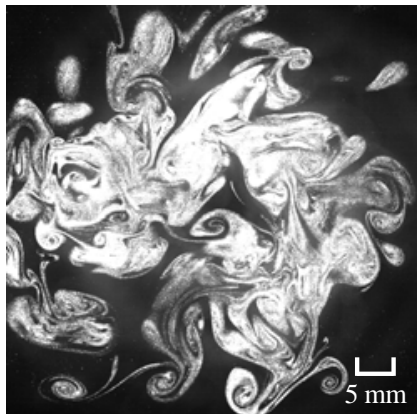

$t=686.00 \mathrm{~ms}$

Fig. 9 Vortical structures evolving from hollow-type streamwise vortex at $V_{i}=V_{o}=1.0 \mathrm{~m} / \mathrm{s}, N=1600 \mathrm{rpm}$ and $Z=1.25$.

の噴流出口より直径の 2 倍以遠の領域である。このとき，渦崩壊によって渦度場が中実型から中空型に大きく変 化することが重要である (文献 8 の図 9 参照). 乱流化はその中空型渦度場の不安定性によって一気に進むように 見える. 中実型縦渦の場合，スワール速度比 $q$ が 0.88 を超えると逆流を伴う渦崩壊が起きる ${ }^{(8)}$. この基準を軸流 速度 $1.0 \mathrm{~m} / \mathrm{s}$ の中実型縦渦に適用寸ると, 渦崩壊開始の臨界値として $V_{\theta, r=D o / 2}=0.88 \mathrm{~m} / \mathrm{s}$ を得る. 一方, 本研究の 中空型縦渦では $V_{i}=V_{o}=1.0 \mathrm{~m} / \mathrm{s}, N=1600 \mathrm{rpm}$ の場合, $V_{\theta, r=D o / 2}=1.68 \mathrm{~m} / \mathrm{s}$ であり, 中実型縦渦の渦崩壊開始の臨 界值よりも大であるが，可視化によれば渦崩壊の兆候はない．環状領域の剛体回転をさらに増していくと，中空 型縦渦に特有の渦崩壊に至ると思われるが，それに直接関わる淀み点・逆流の発生は環状領域における軸流速度 と周速度の動径方向分布の影響を受ける．今後このような視点から中空型縦渦の渦崩壊（淀み点の発生）を調べ る必要がある.

中空型縦渦の乱流遷移によってどの程度のスケールを持つ組織渦構造が形成されるのかを明らかにすることは, その流体混合の能力を理解寸る上で重要である. 図 9 からわかるように, 乱流遷移によって流体の混合促進に大 きく寄与する渦構造が $Z=1.25$ で現れる，そこで，図 9 に示す横断面像の 4 枚を対象に，目視によって観察され る渦パターンの最大寸法を渦径と定義し, その渦径を測定することにした. 総数約 120 個の渦径のデータを $0.1 D_{o}$ 幅の 7 区間 $\left(0.05 D_{o} \sim 0.15 D_{o}, \cdots, 0.65 D_{o} \sim 0.75 D_{o}\right)$ に仕分けし，各区間の渦の個数を調べた相対度数分布を図 10 に示す．なお，横断面像の空間分解能は 1 pixel あたり約 $0.07 \mathrm{~mm}$ であり，渦径の測定には十分な空間分解能 を有する. 図 10 より，渦径データは対数正規確率密度分布（平均と分散がデータと同一）にほぼ従い，この段階 の渦形成が不規則過程であることを示唆している. 出現確率が最も高いのは径が $D_{o} / 4$ の渦である. 従来の研究 ${ }^{(2)}$

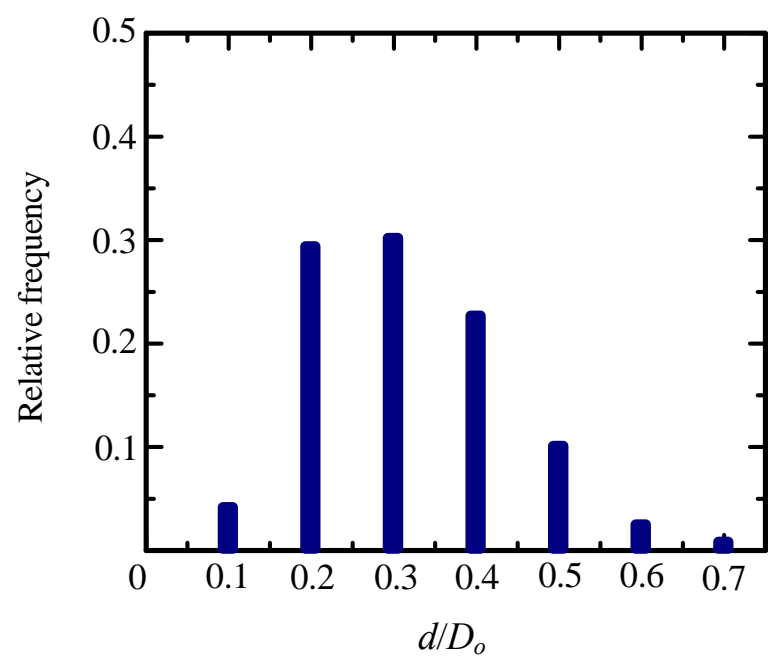

Fig. 10 Relative frequency distribution for diameter of coherent vortices at $V_{i}=V_{o}=1.0 \mathrm{~m} / \mathrm{s}, N=1600 \mathrm{rpm}$ and $Z=1.25$. 
によると, 中空型縦渦の線形不安定の増幅摚乱のスケールは $D_{o} / 4$ 程度（環状領域の動径幅の半分）である. 前者 が非線形の不規則過程で観察される渦であることを考えると, この一致は大変興味深い. 剛体回転 $(N=1600 \mathrm{rpm})$ の渦度を仮定する場合, 径が $D_{o} / 4$ である渦の渦レイノルズ数は 440 と評価される. 一方, 発達した乱流境界層の 壁近傍でレイノルズ応力の生成と運動量輸送を主に担うのは, 渦レイノルズ数が高々 200 程度の縦渦である ${ }^{(10)}$. つまり，壁乱流よりも強い縦渦群による乱流場が形成されるとみてよい。このような組織渦で満たされた乱流場 が中空型縦渦の不安定化によって噴流出口近くの $Z=1.25$ において形成されており, 流れは高い混合能を有する と言える. 本論文では混合遷移が起きない条件の下で実験を行っている. しかし，図 9 における $0.1 d / D_{o}$ のスケー ルの渦は渦レイノルズ数でみると 70 程度であり, 混合遷移後に現れる乱流微細渦の典型的な值と一致しており, 注目される. 流れが混合遷移の状態に近づくと，このスケールの渦が数を増すはずである.

\section{4. まとめ}

本研究では, 混合促進制御の観点から, 不安定性の強い渦構造として, 縦渦の中心軸から離れた環状領域のみ に剛体回転の流れ方向渦度を有寸る “中空型縦渦 (2) ” に着目し, 環状領域の渦度の増加によって生じる中空型 縦渦の不安定挙動と乱流遷移を実験的に調べた。噴流出口における中空型縦渦の環状領域（剛体回転を伴う環状 噴流）の外径 $D_{o}=20 \mathrm{~mm}$, 中心領域（中心噴流）の直径 $D_{i}=10 \mathrm{~mm}$, 中心噴流と環状噴流の平均軸流速度 $V_{i}$, $V_{o}$ を $V_{i}=V_{o}=0.5,1.0 \mathrm{~m} / \mathrm{s}$ とした. このとき, 噴流出口における軸流レイノルズ数 $R e_{o}$ は 666, 1332 である. また, 噴流出口における環状領域外縁の周速度 $V_{\theta, r=D o / 2}$ を $0 \sim 1.68 \mathrm{~m} / \mathrm{s}$, 剛体回転の流れ方向渦度 $\Omega$ を $0 \sim 335 \mathrm{~s}^{-1}$, 循環 $\Gamma$ を $0 \sim 0.105 \mathrm{~m}^{2} / \mathrm{s}$, 渦レイノルズ数 $R e_{\Gamma}$ を $0 \sim 7000$ の範囲でそれぞれ変化させた. 本研究で得られた主要な結果を 以下に示寸.

（1）中空型縦渦の環状領域の渦度（あるいは剛体回転の角速度）を増加させていくと，流れの非線形発達の過程 で重要となる多角形パターンが環状領域の外縁に形成される.さらに環状領域の渦度を増加させると, 多角形の 頂点付近から渦巻きが形成され, 中心領域の外縁の形状も多角形状になる. そして, 中心領域と環状領域の界面 にも組織渦が生まれる。これらの組織渦は中空型縦渦の不安定性に特有の縦渦群であり, 生成・合体・融合を準 周期的に繰り返す. 寸なわち, このような縦渦群による乱流場が噴流出口付近において形成されるようになる.

(2) 中空型縦渦の不安定性, 組織渦の生成過程およびその後の流れの非線形発達を理解し, 記述する上で重要と なる因子はスワール速度比 $q\left(=V_{\theta, r=D_{0} / 2} / V_{o}\right)$ である.このスワール速度比は軸流と周方向流の時間スケール $\left(D_{o} / V_{o}\right.$ と $2 / \Omega)$ の比, あるいは渦レイノルズ数 $R e_{\Gamma}$ と軸流レイノルズ数 $R e_{o}$ の比で表わされる因子であり, 流れの相似 性を支配する。

(3) 中空型縦渦の遷移過程で生まれる組織渦が流れを支配する段階になると, 組織渦の渦径の相対度数分布は, 対数正規確率密度分布にほぼ従っており, この段階における渦の形成は不規則過程とみなせる. 出現確率が最も 高い渦は径の大きさが $D_{\delta} / 4$ の渦であった. 環状領域において剛体回転（ $N=1600 \mathrm{rpm} ）$ の渦度を仮定した場合, 渦レイノルズ数は 440 と評価される. つまり, 壁乱流 ${ }^{(10)}$ の縦渦よりも強い縦渦群による乱流場が形成される.

\section{謝 辞}

著者の比江島俊彦と西岡通男は, 科学研究費（課題番号 S21226020）の研究助成を受けた. また, 酸化チタン 粒子の微細構造の撮影には, 立命館大学 理工学部 機械工学科 吉原研究室が保有する走査型電子顕微鏡 (Keyence VE-7800）を使用させて頂きました。 ここに深く感謝の意を表す.

\section{文献}

(1) Dimotakis, P. E., “The mixing transition in turbulent flows”, Journal of Fluid Mechanics, Vol. 409 (2001), pp. 69-98. 
(2) 西岡通男, 松岡光大, 辻本健士, 比江島俊彦, “不安定な縦渦と混合促進制御へのその応用について”, 日本 機械学会論文集 B 編，Vol. 63, No. 605 (1997), pp. 119-125.

(3) Michalke, A., and Timme, A., "On the inviscid instability of certain two-dimensional vortices-type flows", Journal of Fluid Mechanics, Vol. 29 (1967), pp. 647-666.

(4) Gotoda, H., Miyano, T., and Shepherd, I.G., "Experimental investigation on dynamic motion of lean swirling premixed flame generated by change in gravitational orientation”, Physical Review E, Vol. 81 (2010), 026211(10 pages).

(5) Matsubara, S., Gotoda, H., Adzula, A., and Ueda, T., "Experiments on dynamic behavior of near-field region in variable property jet with swirling flow”, Experiments in Fluids, Vol. 51 (2011), pp. 881-891.

(6) Billant. P., Chomaz. J. M., and Huerre. P., “Experimental study of vortex breakdown in swirling jets”, Journal of Fluid Mechanics, Vol. 376 (1998), pp. 183-219.

(7) Loiseleux. T. and Chomaz. J. M. "Breaking of rotational symmetry in a swirling jet experiment”, Physics of Fluids, Vol. 15 (2003), pp. 511-523.

(8) H. Liang., and Maxworthy. T., "An experimental investigation of a swirling jets”, Journal of Fluid Mechanics, Vol. 525 (2005), pp. 115-159.

(9) H. Liang., and Maxworthy. T., "Experimental investigations of a swirling jet in both stationary and rotating surroundings", Experiments in Fluids, Vol. 45 (2008), pp. 283-293.

(10) Robinson, S. K., “Coherent motions in the turbulent boundary layer”, Annual Review Fluid Mechanics, Vol. 23 (1991), pp. 601-639. 